\title{
ANALISIS FAKTOR-FAKTOR KEAKTIFAN \\ PETUGAS PEMANTAU JENTIK \\ DALAM UPAYA PENGENDALIAN PENYAKIT DEMAM BERDARAH \\ DI KABUPATEN TANGERANG
}

\author{
Oleh \\ WAHIDIN ${ }^{1}$ \\ ${ }^{1}$ Staff Pengajar Fakultas Ilmu Kesehatan Universitas Muhammadiyah Tangerang \\ E-mail : didin.wahidin1977@gmail.com
}

\begin{abstract}
ABSTRAK
Kabupaten Tangerang termasuk endemis DBD dari 29 kecamatan yang ada di Kabupaten Tangerang hampir separuhnya terjadi kasus Demam berdarah, pada tahun 2016 Kabupaten ini terjadi KLB DBD sehingga Pemerintah Daerah mengerahkan Petugas Pemantau Jentik dalam jumlah yang cukup banyak.

Paneitian ini dilakukan di Kabupaten Tangerang bertujuan mengetahui sekaligus menganalisis faktor-faktor keaktifan petugas Pemantau Jentik dalam pengendalian DBD, penelitian menggunakan metode survai analitik dengan quisioneer sebagai instrument utama.

Hasil penelitian menunjukkan bahwa faktor keaktifan petugas dalam pengendalian DBD di Kabupaten Tangerang sudah berjalan cukup baik, ditemukan faktor yang secara dominan memengaruhi Keaktifan petugas Pemantau Jentik, faktor tersebut adalah sistem kepemimpinan sebesar 41,4\%, pengetahuan petugas $26,9 \%$, dukungan keluarga 18,8\% dan motipasi pribadi sebesar 13,3\%. .

Berdasarkan hasil tersebut dapat disimpulkan bahwa faktor yang mempengaruhi keaktifan petugas pemantau jentik di Kabupaten Tangerang terdiri dari sistem kepemimpinan, pengetahuan petugas, dukungan keluarga dan motipasi pribadi sedangkan faktor dominan yang memengaruhi petugas pemantau jentik adalah sistem kepemimpinan dan pengetahuan petugas.
\end{abstract}

Kata kunci : Faktor-faktor keaktifan petugas dan Upaya Pengendalian DBD

\section{PENDAHULUAN}

Berkembangnya Penyakit Demam berdarah dengue (DBD) di Indonesia begitu nyata telah menjadikan penyakit ini menjadi salah satu sumber masalah kesehatan masyarakat di Indonesia. Perkembangan ini sebenarnya sudah sejak lama ada dan di Indonesia sendiri sejak tahun 1968 jumlah kejadiannya cenderung meningkat kemudian penyebarannya terus bertambah luas. Kondisi ini disebabkan karena semakin tersebar luasnya virus penyebab DBD yang dibawa oleh vector penyebabnya yaitu nyamuk Aedes Agypty ke berbagai belahan wilayah yang ada di Indonesia. Perkembangan yang pesat ini erat kaitannya dengan terjadinya peningkatan mobilitas penduduk sejalan dengan semakin lengkapnya fasilitas transportasi yang modern dan cepat (Depkes RI, 2005).

Penyakit DBD dapat menimbulkan kematian dalam waktu singkat dan sering menimbulkan wabah Oleh sebab itulah Penyakit Demam Berdarah Dengue (DBD) 
saat ini menjadi salah satu prioritas nasional pengendalian penyakit menular di Indonesia. Upaya pengendalian DBD masih perlu ditingkatkan, mengingat daerah penyebarannya saat ini terus bertambah luas dan Kejadian Luar Biasa (KLB) masih sering terjadi (Kementerian Kesehatan Republik Indonesia 2016 ).

Provinsi Banten merupakan daerah endemis penyakit DBD dan Kabupaten
Tangerang merupakan salah satu wilayah Endemis DBD di Propinsi Banten. dengan Jumlah kasus relatif tinggi dan sering terjadi KLB yang memakan korban jiwa. Jumlah penderita penyakit Demam Berdarah Dengue (DBD) di Kabupaten Tangerang selama sepuluh tahun terakhir dapat dianalisa pada tabel berikut ini :

\section{Tabel 1}

Data Kasus Demam Berdarah Dengue

di Kabupaten Tangerang Tahun 2006 - 2010

\begin{tabular}{ccccc}
\hline Tahun & $\begin{array}{c}\text { Jumlah } \\
\text { Penderita }\end{array}$ & Meninggal & $\begin{array}{c}\text { IR per 100.000 } \\
\text { Penduduk }\end{array}$ & $\begin{array}{c}\text { CFR } \\
(\mathbf{\%})\end{array}$ \\
\hline 2006 & 740 & 8 & 22.17 & 1.08 \\
2007 & 986 & 18 & 28.00 & 1.82 \\
2008 & 980 & 14 & 26.80 & 1.40 \\
2009 & 884 & 7 & 34.00 & 0.79 \\
2010 & 999 & 5 & 38.00 & 0.50 \\
\hline
\end{tabular}

Sumber: Bid.P2- P2P Dinas Kesehatan Kab.Tangerang 2010

Dari Tabel 1 di atas terlihat bahwa tahun 2010 Insiden Rate (IR) per 100.000 penduduk mengalami peningkatan dibandingkan tahun 2009 yaitu dari $34 / 100.000$ penduduk menjadi 38/100.000 penduduk. CFR DBD di tahun 2010 mengalami penurunan menjadi $0.5 \%$ dibandingkan tahun 2009 sebesar $1 \%$. Namun pada tahun 2010 jumlah penderita DBD meningkat tajam menjadi 999 orang.

Tabel 2

Data Kasus Demam Berdarah Dengue

di Kabupaten Tangerang Tahun 2011 - 2014

\begin{tabular}{ccccc}
\hline Tahun & $\begin{array}{c}\text { Jumlah } \\
\text { Penderita }\end{array}$ & Meninggal & $\begin{array}{c}\text { IR per 100.000 } \\
\text { Penduduk }\end{array}$ & $\begin{array}{c}\text { CFR } \\
(\boldsymbol{\%})\end{array}$ \\
\hline 2011 & 202 & 0 & 7.10 & 0 \\
2012 & 640 & 6 & 21.10 & 0.48 \\
2013 & 936 & 3 & 29.80 & 0.32 \\
2014 & 409 & 3 & 13.00 & 0.73 \\
\hline
\end{tabular}

Sumber: Bid.P2- P2P Dinas Kesehatan Kab.Tangerang 2014

Dari tabel 2 di atas dapat dilihat Insiden Rate (IR) mengalami penurunan dibandingkan tahun 2013 yaitu 29,8/100.000 penduduk menjadi $13 / 100.000$ penduduk, tetapi masih dibawah IR Nasional yang sebesar ( 5/100.000 penduduk ). CFR (Case Fatality Rate) DBD adalah angka kematian akibat
DBD; yaitu angka kematian dibagi dengan jumlah kasus dikali dengan 100. Pada tahun 2014 CFR DBD mengalami peningkatan menjadi $0,73 \%$ dibandingkan tahun 2013 sebesar 0,32 \% (Angka Nasional CFR DBD adalah < $1 \%$ ). (Bid.P2- P2P Dinas Kesehatan Kab.Tangerang 2014). 
Upaya yang dilakukan adalah dengan melakukan pencegahan, pengendalian dan pemberantasan penyakit DBD yang dititik beratkan pada kegiatan Pemberantasan Sarang Nyamuk (PSN) disemua wilayah, dan pemantauan jentik berkala untuk mencapai Angka Bebas Jentik sesuai target (>95\%). Kegiatannya dilakukan dengan melakukan Sosialisasi dan Gerakan Desa Bebas Jentik bagi kader,melakukan Penyelidikan Epidemologi (PE) dan melaksanakan Fogging Fokus sesuai kriteria dari hasil penyelidikan Epidemologi (Dinas Kesehatan Kabupaten Tangerang 2014).

Upaya pengendalian dan pencegahan DBD terus menerus digalakkan dan dilaksanakan secara terorganisir di kota maupun di desa, mencakup penyuluhan dan pendidikan pengelolaan penderita bagi dokter dan paramedis, dan pemberantasan sarang nyamuk dengan peran serta masyarakat, sehingga diharapkan angka penderita DBD di Indonesia dari tahun ke tahun akan terus menurun.

Kegiatan pengendalian Penyakit Demam Berdarah Dengue di Indonesia bertumpu pada kegiatan pokok yang isinya tertuang dalam Keputusan Menteri Kesehatan nomor 581/MENKES/SK/VII/1992 tentang Pemberantasan Demam Berdarah Dengue. Prioritas utama kegiatan pengendalian ditekankan pada upaya pencegahan atau upaya prepentiv melalui peningkatan pemberdayaan dan peran serta masyarakat, gerakan Pemberantasan Sarang Nyamuk (PSN), penatalaksanaan penderita DBD dengan meningkatkan akses masyarakat terhadap pelayanan kesehatan yang berkualitas dan terjangkau, memperkuat kegiatan Surveilans Epidemiologi dan penguatan Sistem Kewaspadaan Dini Kejadian Luar Biasa (SKD-KLB) DBD, serta memperkuat kapasitas SDM.

Sampai dengan saat ini berbagai upaya telah dilakukan untuk menanggulangi terjadinya peningkatan kasus DBD dimasyarakat, salah satu diantaranya adalah dengan peningkatan kegiatan dengan pendekatan untuk memberdayakan masyarakat dalam kegiatan Pemberantasan Sarang Nyamuk (PSN), gerakan 3M (Menguras-Menutup-Mengubur).

Sebenarnya kegiatan penanggulangan DBD telah diintensifkan sejak tahun 1992 dan kemudian pada tahun 2000-an dikembangkan menjadi kegiatan 3M Plus yaitu dengan cara menggunakan larvasida, melakukan pendekatan biologis dengan memelihara ikan/tumbuhan dan melakukan upaya pencegahan gigitan nyamuk. Sampai saat ini upaya tersebut belum menampakkan hasil yang diinginkan karena setiap tahun masih terjadi peningkatan angka kejadian Demam Berdarah. Membasmi jentik nyamuk tidaklah cukup dilakukan pemerintah saja, melainkan butuh partisipasi dan keaktivan seluruh masyarakat juga, perlu kesediaan, kemauan dan tindakan nyata. Program pemberantasan sarang nyamuk (PSN) tidak cukup dilakukan satu-dua kali, melainkan harus rutin atau berkala terlebih setiap musim jangkitan DBD.

Selama ini berbagai upaya untuk memberdayakan masyarakat dalam PSNDBD sudah banyak dilakukan tetapi hasilnya belum optimal dapat merubah perilaku masyarakat untuk secara terus menerus melakukan PSN-DBD di tatanan dan lingkungan masing-masing, keaktifan petugas pemantau jentik yang ideal seharusnya dapat mengayomi dan mampu meningkatkan kerjasama antar masyarakat yang ada sehingga kegiatan dapat berjalan dengan baik.

Pengamatan pendahuluan sederhana yang dilakukan peneliti secara langsung dilapangan pada bulan Desember 2016 di beberapa wilayah kerja Puskemas yang dilakukan secara random yaitu Puskesmas Tigaraksa, Pasir Nangka, Kelapa Dua, Bojong Nangka, Rajeg dan Pasar Kemis Diperoleh data dan informasi hasil pengamatan bahwa di wilayah tersebut mobilisasi penduduk cukup tinggi,kerapatan lingkungan tempat tinggal yang relative padat karena wilayah tersebut 
termasuk wilayah industri. Dibeberapa rumah penduduk dan tempat-tempat umum lingkungan sekitar masih ada wadah wadah bekas yang berisi jentik nyamuk sehingga perlu melakukan PSN secara rutin.

Kelembagaan Pokja DBD sebenarnya sudah ada terbentuk namun pelaksanaannya kurang optimal. Pemeriksaan jentik nyamuk oleh Kader DBD dalam hal ini petugas pemantau jentik kurang berjalan optimal,hanya bila ada kasus dan segera dilaksanakan fogging. Management Pokja DBD di lapangan belum dilaksanakan optimal karena banyaknya beban kerja dan program sehingga kegiatan Pokja DBD sering terabaikan.

Pokja DBD para petugas pemantau jentik di desa dan atau kelurahan kebanyakan adalah karyawan aktiv; PNS akibatnya evaluasi kegiatan jarang terpantau.Kerja bakti kebersihan lingkungan dalam pemberantasan sarang nyamuk dijadwalkan seminggu sekali dalam kegiatan Jum'at bersih, tetapi dalam pelaksanaannya masih sangat tergantung pada ketua RT/RW masing-masing.

Kader juru pemantau jentik (Jumantik) / Petugas Pemantau Jentik yang aktif diharapkan akan memengaruhi menurunkan angka kasus DBD, oleh karena itu diperlukan upaya peningkatan keaktifan jumantik melalui motivasi yang dilakukan oleh dinas kesehatan. Penelitian ini diarahkan khusus pada petugas pemantau jentik yang tinggal di wilayah Kabupaten Tangerang. Penelitian ini dibatasi pada pembahasan mengenai faktor-faktor apa saja yang berhubungan dengan kektifan kader Jumantik / Petugas Pemantau Jentik dalam upaya pengendalian penyakit DBD di Kabupaten Tangerang.

Maka berdasarkan uraian itulah peneliti merasa tertarik untuk dapat meneliti lebih lanjut tentang faktor-faktor apa saja yang memengaruhi keaktifan petugas pemantau jentik dalam upaya pengendalian Penyakit
Demam Berdarah di Kabupaten Tangerang sehingga dapat optimal dalam memberantas dan mengendalikan frekuensi kejadian Penyakit Demam Berdarah. Penelitian ini bertujuan untuk mengetahui dan mengukur faktor-faktor yang memengaruhi keaktifan petugas pemantau jentik/kader Jumantik dalam upaya pengendalian Penyakit Demam Berdarah Dengue di Kabupaten Tangerang.

\section{METODE PENELITIAN.}

\section{Jenis Penelitian}

Jenis penelitian yang akan dilakukan dalam kegiatan kali ini adalah jenis penelitian lapangan Explanatory Research analitik yaitu penelitian yang akan dilakukan melalui kegiatan survey dimana penelitian ini bertujuan untuk dapat menjelaskan adanya hubungan atau pengaruh antara variabel terikat (dependent) dan variabel bebas (independent) melalui pengujian hipotesis yang telah diajukan.

\section{Pendekatan Penelitian}

Pendekatan dalam penelitian ini adalah penelitian survey. Pendekatan penelitian ini menggunakan pendekatan mixed research analisys antara pendekatan penelitian kuantitatif dan pendekatan penelitian kualitatif dengan rancangan penelitian Cross-Sectional pendekatan ini sengaja dilakukan untuk mengantisipasi lebih jauh apabila hasil penelitian secara kuantitatif menunjukan hasil yang kurang memuaskan.

\section{Lokasi Penelitian}

Penelitian ini dilakukan di wilayah Kabupaten Tangerang dengan mengambil sampel lokasi di beberapa kecamatan yang dipilih sesuai jumlah kasus kejadian demam berdarah paling tinggi dan paling rendah. Berdasarkan data yang diberikan oleh Dinas Kesehatan Kabupaten Tangerang. Daerah kecamatan yang paling tinggi kasus kejadian DBD-nya dibanding 
wilayah kecamatan lain adalah 8 wilayah kecamatan yaitu Balaraja, Tigaraksa, Pasar Kemis, Curug, Cikupa, Panongan, Legok dan Kelapa Dua. Dan sebagai wilayah kontrol dipilih 8 wilayah kecamatan yang jarang atau tidak ada terjadi kasus DBD yaitu wilayah kecamatan Jambe, Kronjo, Kemiri, Teluk Naga, Kosambi, Gunung Kaler, Kresek dan Sepatan Timur.

\section{Populasi dan Sampel}

Populasi merupakan kumpulan dari keseluruhan obyek yang akan diukur dalam penelitian untuk kepentingan tersebut maka populasi dalam penelitian ini adalah seluruh masyarakat yang diangkat dan bertugas sebagai petugas pemantau jentik yang tinggal di wilayah kerja Puskesmas di Kabupaten Tangerang

Sampel dalam penelitian ini akan diambil dari Petugas Pemantau Jentik, sebanyak 185 orang yang tersebar di daerah kecamatan yang paling tinggi angka kejadian DBD-nya dibanding wilayah kecamatan lain dalam hal ini adalah wilayah kecamatan Balaraja, Tigaraksa, Pasar Kemis, Curug, Cikupa, Panongan, Legok dan Kelapa Dua.

\section{HASIL DAN PEMBAHASAN}

\section{Hasil Analisis Univariat}

Hasil analisis secara univariat terpapar dalam paparan seperti berikut ini.

\section{a. Gambaran Geografis Demografis Wilayah Penelitian.}

Kabupaten Tangerang merupakan salah satu wilayah di Propinsi Banten terletak di bagian Timur Propinsi Banten pada koordinat $106^{\circ} 20^{\prime}-106^{\circ} 43^{\prime}$ Bujur Timur dan $6^{\circ} 20^{\prime}-6^{\circ} 20^{\prime}$ lintang selatan dengan luas wilayah $959.60 \mathrm{~km} 2$ dengan batas-batas wilayah : Sebelah Utara berbatasan dengan Laut Jawa, Sebelah Timur berbatasan dengan DKI Jakarta,Kota Tangerang dan Kota Tangerang Selatan, Sebelah Selatan berbatasan dengan Kabupaten Bogor dan
Kabupaten Lebak, Sebelah Barat dengan Kabupaten Serang.

Kabupaten Tangerang secara geografis memiliki topografi yang relatif datar dengan kemiringan tanah rata-rata 0-8\% menurun ke Utara. Ketinggian wilayah berkisar antara 0-50 $\mathrm{m}$ di atas permukaan laut. Daerah Utara Kabupaten Tangerang merupakan daerah pantai dan sebagian besar daerah urban, daerah timur adalah daerah rural dan pemukiman sedangkan daerah barat merupakan daerah industri dan pengembangan perkotaan. Secara administratif pada tahun 2016 Kabupaten Tangerang memiliki 29 wilayah Kecamatan yang terdiri dari 274 wilayah Desa dan Kelurahan (Propil Kabupaten Tangerang 2016).

Dari sisi kependudukan Data dari BPS 2015 menunjukan bahwa struktur penduduk di Kabupaten Tangerang termasuk struktur penduduk "usia produktif" dengan 68,75\% penduduk adalah kelompok umur 15-64 tahun, jumlah penduduk berumur 0-14 tahun sebanyak $28.74 \%$ dan berumur $>65$ tahun adalah sebanyak 2,51\%. Jumlah penduduk Kabupaten Tangerang pada tahun 2014 adalah 3.140.472 jiwa yang terdiri dari 1.608.149 jiwa laki-laki dan 1.532.323 jiwa perempuan, terjadi kenaikan bila dibandingkan dengan tahun 2013. Kepadatan penduduk Kabupaten Tangerang rata-rata $3.273 \mathrm{jiwa} / \mathrm{km}^{2}$. Kecamatan dengan kepadatan penduduk tertinggi berturut-turut adalah Pasar Kemis, Cikupa dan Kelapa Dua.

\section{b. Sebaran kasus DBD di Kabupaten Tangerang.}

Kabupaten Tangerang terdiri dari 29 Kecamatan dengan 274 wilayah desa dan kelurahan dan terdapat 43 Pusat Kesehatan Masayarakat, wilayah kecamatan terluas adalah Kecamatan Mauk, Rajeg, Tigaraksa, Pakuhaji, dan Kecamatan Kronjo. Dilihat dari kasus DBD hampir seluruh wilayah kecamatan di Kabupaten Tangerang ada terdapat kasus DBD. 
Data Dinas Kesehatan Kaputen Tangerang Tahun 2016 mengungkapkan bahwa Wilayah yang paling banyak kasus DBD adalah Kecamatan Balaraja sebanyak 36 kasus, Tigaraksa 42 kasus, Pasar Kemis 20 kasus, Curug 27 kasus, Cikupa 87 kasus, Panongan 30 kasus, Legok 22 kasus dan Kecamatan Kelapa Dua sebanyak 77 kasus, dari wilayah tersebut ternyata kecamatan dengan kasus tertinggi adalah kecamatan cikupa sebanyak 87 kasus dan Kelapa Dua sebanyak 77 kasus. Kecamatan dengan kasus DBD nol adalah wilayah kecamatan Jambe, Kecamatan Kronjo, Kecamatan Kemiri, Kecamatan Teluk Naga, Kecamatan Kosambi, dan Kecamatan Gunung Kaler.

Jika dilihat dari sebaran penduduknya wilayah yang paling banyak penduduknya adalah kecamatan Pasarkemis jumlah penduduknya sebanyak 281.031 jiwa, kecamatan Cikupa sebanyak 250.033 jiwa, Kecamatan Kelapadua 202.501 Jiwa, dan Kecamatan Curug sebanyak 185.864 jiwa. Dari data tabel diatas diketahui juga beberapa puskesmas di Kabupaten Tangerang yang wilayah kerjanya terbebas dari kasus DBD, puskemas itu terdiri dari : Puskesmas Jambe, Puskesmas Kronjo, Puskesmas Kemiri, Puskesmas Sukatani, Puskesmas Teluk Naga, PKM Tegal Angus, PKM Kosambi, PKM Salembaran Jaya, PKM Sukawali, PKM Suradita dan PKM Gunung Kaler.

\section{c. Karakteristik responden penelitian.}

Sebagai hasil penelitian didapatkan data pada distribusi karakteristik responden yang berdasarkan pada karakteristis Sosidemografi, kehidupan ekonomi dan keikutsertaan pelatihan penanganan DBD. Responden penelitian ini berjumlah 185 orang juru pemantau jentik yang dipaparkan seperti berikut ini. Karakteristik sosiodemografis petugas pemantau jentik terdiri dari jenis kelamin, usia responden, Pendidikan formal, status perkawinan jumlah tanggungan keluarga. Berdasarkan jenis kelamin ternyata petugas pemantau jentik didominasi kaum perempuan yaitu sebanyak 102 responden $55,1 \%$ berjenis kelamin perempuan dan 83 responden atau sebanyak 44,9\% berjenis kelamin laki-laki. Berdasarkan usia responden terbanyak adalah pada kelompok lansia awal (41 - 50 tahun) sebanyak 52 responden $(28,1 \%)$ dan 51 responden atau $27,6 \%$ pada usia dewasa akhir (31 - 40 tahun). Berdasarkan pendidikan, responden menunjukkan sebagian besar berlatar belakang pendidikan Sekolah Dasar (SD) yaitu 73 responden (39,5\%), kemudian berpendidikan SMP sebanyak 55 orang $(29,7 \%)$ dan SMA sederajat 38 orang atau $20,5 \%$ dan selebihnya tidak tamat SD, tamat diploma dan sarjana.

Kondisi Pendidikan responden ini dapat memengaruhi pemahaman responden terhadap paparan informasi kesehatan yang diperolehnya. Berdasarkan status kawin, responden sebagian besar sudah menikah berjumlah 149 responden (80,5\%), 11,9\% berstatus duda/janda dan 7,6\% status belum menikah. Dari sisi jumlah tanggungan keluarga 97 orang responden atau 52,4\% responden memiliki jumlah tanggungan sebanyak 1-2 orang, 29,7\% memiliki tanggungan sebanyak 3-4 orang, 4,3\% responden memiliki tanggungan sebanya lebih dari 6 orang. Dari sisi penghasilan $40,5 \%$ responden memiliki penghasilan antara $2-3$ juta rupiah perbulannya, $34,1 \%$ berpenghasilan antara $3-4$ juta, 10,3\% berpenghasilan $4-5$ juta, sementara $13 \%$ responden mengaku penghasilannya hanya sebesar $1-2$ juta dan 2,2\% mengaku penghasilannya diatas 5 juta perbulannya.

\section{d. Faktor-faktor keaktifan Petugas Pemantau Jentik.}

Faktor-faktor keaktifan petugas dapat dianalisa dalam tabel berikut ini. 
Table 3

Faktor-faktor Keaktifan petugas pemantau jentik dalam upaya pengendalian Penyakit Demam Berdarah Dengue di kabupaten Tangerang

\begin{tabular}{|c|c|c|c|c|c|c|c|c|c|}
\hline \multirow[t]{3}{*}{ No } & \multirow{3}{*}{$\begin{array}{l}\text { Variabel Dan } \\
\text { Indikator }\end{array}$} & \multicolumn{6}{|c|}{$\begin{array}{l}\text { Faktor-faktor Keaktifan } \\
\text { Petugas pemantau jentik }\end{array}$} & \multirow{2}{*}{\multicolumn{2}{|c|}{ Total }} \\
\hline & & \multicolumn{2}{|c|}{ Baik } & \multicolumn{2}{|c|}{$\begin{array}{c}\text { Cukup } \\
\text { Baik }\end{array}$} & \multicolumn{2}{|c|}{$\begin{array}{l}\text { Kurang } \\
\text { Baik }\end{array}$} & & \\
\hline & & $\mathbf{F}$ & $\%$ & $\mathbf{F}$ & $\%$ & $\mathbf{F}$ & $\%$ & $\mathbf{F}$ & $\%$ \\
\hline 1 & $\begin{array}{l}\text { Pelatihan dan kejelasan } \\
\text { pengembangan karier }\end{array}$ & 20 & 10,8 & 98 & 53,0 & 67 & 36,2 & 185 & 100 \\
\hline 2 & $\begin{array}{l}\text { Pengakuan eksistensi } \\
\text { diri }\end{array}$ & 23 & 12,4 & 95 & 51,4 & 67 & 36,2 & 185 & 100 \\
\hline 3 & Etos dan minat kerja. & 15 & 8,1 & 88 & 47,6 & 82 & 44,3 & 185 & 100 \\
\hline 4 & $\begin{array}{l}\text { Pembagian wilayah } \\
\text { kerja }\end{array}$ & 15 & 8,1 & 87 & 47,0 & 83 & 44,9 & 185 & 100 \\
\hline 5 & Uraian pedoman kerja & 30 & 16,2 & 98 & 53,0 & 57 & 30,8 & 185 & 100 \\
\hline 6 & Dukungan keluarga & 33 & 17,8 & 86 & 46,5 & 66 & 35,7 & 185 & 100 \\
\hline 7 & $\begin{array}{l}\text { Kompensasi imbalan } \\
\text { dan reward yang } \\
\text { diterima }\end{array}$ & 17 & 9,2 & 102 & 55,1 & 66 & 35,7 & 185 & 100 \\
\hline 8 & $\begin{array}{l}\text { Ketersediaan Fasilitas } \\
\text { Kerja }\end{array}$ & 18 & 9,7 & 107 & 57,8 & 60 & 32,4 & 185 & 100 \\
\hline 9 & Sistem Kepemimpinan & 34 & 18,4 & 89 & 48,1 & 62 & 33,5 & 185 & 100 \\
\hline 10 & Lingkungan Kerja & 28 & 15,1 & 95 & 51,4 & 62 & 33,5 & 185 & 100 \\
\hline 11 & Motivasi Pribadi & 19 & 10,3 & 108 & 58,4 & 58 & 31,4 & 185 & 100 \\
\hline 12 & Pengetahuan Petugas & 29 & 15,7 & 105 & 56,8 & 51 & 27,6 & 185 & 100 \\
\hline
\end{tabular}

Sumber : Data Primer Terolah

Berdasarkan Tabel 3 Faktor-faktor keaktifan petugas dianalisa dari faktorfaktor seperti berikut ini : Pelatihan dan kejelasan pengembangan karier, Pengakuan eksistensi diri, Etos dan minat kerja, Pembagian wilayah kerja, Uraian pedoman kerja, Dukungan keluarga,

Table 4

Gambaran Faktor-faktor Keaktifan petugas pemantau jentik dalam upaya pengendalian Penyakit Demam Berdarah Dengue di kabupaten Tangerang

\begin{tabular}{|c|c|c|}
\hline $\begin{array}{c}\text { Gambaran Faktor-faktor } \\
\text { Keaktifan petugas pemantau jentik }\end{array}$ & $\begin{array}{l}\text { Jumlah } \\
\mathrm{N}=185\end{array}$ & $\%$ \\
\hline Berjalan Baik & 29 & 15,7 \\
\hline Berjalan Cukup Baik & 136 & 73,5 \\
\hline Berjalan Kurang Baik & 20 & 10,8 \\
\hline Jumlah & 185 & 100 \\
\hline
\end{tabular}

Sumber : Data Primer Terolah

Berdasarkan Table 4 diatas diketahui bahwa Faktor-faktor keaktifan petugas yang terdiri dari kegiatan Pelatihan dan
Kompensasi imbalan dan reward yang diterima, Ketersediaan Fasilitas Kerja, Sistem Kepemimpinan, Lingkungan Kerja, Motivasi Pribadi, dan Pengetahuan Petugas. Dari hasil pemaparan diatas dapat dianalisa kembali pada tabel 4. berikut ini :

kejelasan pengembangan karier, Pengakuan eksistensi diri, Etos dan minat kerja, Pembagian wilayah kerja, Uraian 
pedoman kerja, Dukungan keluarga, Kompensasi imbalan dan reward yang diterima, Ketersediaan Fasilitas Kerja, Sistem Kepemimpinan, Lingkungan Kerja, Motivasi Pribadi, dan Pengetahuan Petugas secara mayoritas sudah berjalan cukup baik.

Hal itu terlihat bahwa dari 185 orang petugas pemantau jentik yang menjadi responden 29 orang atau $15,7 \%$ menilai faktor-faktor tersebut sudah Berjalan dengan Baik, 136 orang responden atau
$73,5 \%$ menilai bahwa faktor-faktor keaktifan sudah berjalan Cukup Baik dan sebanyak 20 orang responden atau $10,8 \%$ menilai bahwa faktor-faktor keaktifan petugas pemantau jentik masih Berjalan Kurang Baik.

\section{e. Upaya Pengendalian DBD}

Upaya kegiatan pengendalian penyakit Demam Berdarah Dengue dapat dianalisa dari tabel berikut ini.

\section{Tabel 5}

Upaya Kegiatan pengendalian

Penyakit Demam Berdarah Dengue di kabupaten Tangerang

\begin{tabular}{|c|c|c|c|c|c|c|c|c|c|}
\hline \multirow{4}{*}{ No } & \multirow{4}{*}{$\begin{array}{l}\text { Variabel Dan } \\
\text { Indikator }\end{array}$} & \multicolumn{6}{|c|}{ Upaya Kegiatan Pengendalian } & \multirow{3}{*}{\multicolumn{2}{|c|}{ Total }} \\
\hline & & \multirow{2}{*}{\multicolumn{2}{|c|}{$\begin{array}{c}\text { Penyaki } \\
\text { Baik }\end{array}$}} & emar & Berd & ah I & & & \\
\hline & & & & \multicolumn{2}{|c|}{$\begin{array}{l}\text { Cukup } \\
\text { Baik }\end{array}$} & \multicolumn{2}{|c|}{$\begin{array}{l}\text { Kurang } \\
\text { Baik }\end{array}$} & & \\
\hline & & $\mathbf{F}$ & $\%$ & $\mathbf{F}$ & $\%$ & $\mathbf{F}$ & $\%$ & $\mathbf{F}$ & $\%$ \\
\hline 1 & $\begin{array}{l}\text { Kegiatan Pengelolaan dan } \\
\text { pengendalian kondisi } \\
\text { Lingkungan }\end{array}$ & 26 & 14,1 & 88 & 47,6 & 71 & 38,4 & 185 & 100 \\
\hline 2 & $\begin{array}{l}\text { Kegiatan Pengelolaan dan } \\
\text { pengendalian DBD secara } \\
\text { Biologis }\end{array}$ & 20 & 10,8 & 95 & 51,4 & 70 & 37,8 & 185 & 100 \\
\hline 3 & $\begin{array}{l}\text { Pengelolaan dan pengendalian } \\
\text { dengan bahan kimia }\end{array}$ & 14 & 7,6 & 99 & 53,5 & 72 & 38,9 & 185 & 100 \\
\hline 4 & $\begin{array}{l}\text { Pengelolaan dan Perlindungan } \\
\text { Diri }\end{array}$ & 35 & 18,9 & 91 & 49,2 & 59 & 18,9 & 185 & 100 \\
\hline 5 & $\begin{array}{l}\text { Pengelolaan dan Pengendalian } \\
\text { terpadu }\end{array}$ & 29 & 30,3 & 100 & 54,1 & 56 & 30,3 & 185 & 100 \\
\hline
\end{tabular}

Sumber : Data Primer Terolah

Berdasarkan Tabel 5 diatas kegiatan pengelolaan dan pengendalian kondisi lingkungan dari 185 orang petugas pemantau jentik 26 orang atau sebanyak $14,1 \%$ menyatakan sudah berjalan baik, 88 orang responden atau $47,6 \%$ responden menilai kegiatan pengendalian kondisi lingkungan sudah berjalan cukup baik dan sebanyak 71 orang responden atau $38,4 \%$ responden menyatakan bahwa pengelolaan dan pengendalian kondisi lingkungn kurang berjalan dengan baik.

Kegiatan pengelolaan dan pengendalian secara biologis dari 185 petugas yang menjadi responden penelitian ini sebanyak 20 orang atau $10,8 \%$ responden menyatakan bahwa kegiatan pengelolaan dan pengendalian DBD secara bilologis sudah berjalan dengan baik, sebanyak 95 orang responden atau sebanyak 51,4\% responden menyatakan bahwa kegiatan pengendalian DBD secara biologis sudah berjalan cukup baik dan sebanyak 70 orang petugas atau $37,8 \%$ petugas menyampaikan bahwa kegiatan pengelolaan dan pengendalian DBD dengan cara biologis berjalan kurang baik. 
Kegiatan pengelolaan dan pengendalian dengan bahan kimia sebanyak 14 orang petugas atau $7,6 \%$ responden menyatakan kegiatan itu sudah berjalan dengan baik dan benar, sebanyak 99 orang petugas atau $53,5 \%$ petugas menilai sudah berjalan cukup baik dan dilakukan dengan benda dan sementara itu sebanyak 72 orang petugas atau sebanyak $38,9 \%$ petugas pemantau jentik menyatakan bahwa kegitan pengendalian secara kimia masih berjalan kurang baik.

Kegiatan pengelolaan perlindungan diri sebanyak 35 orang atau $18,9 \%$ menilai upaya kegiatan perlindungan diri dari gigitan nyamuk sudah berjalan dengan baik, sebanyak 91 orang responden atau $49,2 \%$ responden menyampaikan bahwa upaya kegiatan perlindungan diri dari gigitan nyamuk sudah berjalan cukup baik, dan sementara itu ada 59 orang petugas atau sebanyak $18,9 \%$ petugas pemantau jentik menyampaikan bahwa kegiatan perlindungan diri yang dilakukan petugas dan masyarakat pada umumnya masih kurang berjalan baik. Kegiatan pengelolaan dan pengendalian DBD secara terpadu senyak 29 orang atau 30,3\% responden pengelolaan dan pengendalian DBD secara terpadu sudah berjalan dengan baik, sebanyak 100 orang responden atau 54,1\% responden menyampaikan bahwa kegiatan pengelolaan dan pengendalian DBD secara terpadu sudah berjalan cukup baik dan ada sebanyak 56 oorang petugas pemantau jentik atau sebanyak 30,3\% yang menyampaikan bahwa kegiatan pengendalian DBD secara terpadu masih berjalan kurang baik. Secara keseluruhan upaya kegiatan pengendalian penyakit Demam Berdarah dapat dianalisa dari tabel berikut ini.

Table 6

Gambaran Upaya Kegiatan pengendalian

Penyakit Demam Berdarah Dengue di kabupaten Tangerang

\begin{tabular}{cccc}
\hline No & $\begin{array}{c}\text { Upaya Kegiatan Pengendalian Penyakit } \\
\text { Demam Berdarah Dengue di kabupaten } \\
\text { Tangerang tahun 2016 }\end{array}$ & $\begin{array}{c}\text { Jumlah } \\
\text { N=185 }\end{array}$ & \% \\
\hline 1 & Berjalan Baik & 32 & 17,3 \\
2 & Berjalan Cukup Baik & 97 & 52,4 \\
3 & Kurang Baik & 56 & 30,3 \\
\hline & Jumlah & $\mathbf{1 8 5}$ & $\mathbf{1 0 0}$ \\
\hline
\end{tabular}

Dikembangkan Untuk Tesis ini.

Berdasarkan Tabel 6 Upaya Kegiatan Pengendalian Penyakit Demam Berdarah Dengue di kabupaten Tangerang yang terdiri dari Kegiatan Pengelolaan dan pengendalian kondisi Lingkungan, Kegiatan Pengelolaan dan pengendalian DBD secara Biologis, Pengelolaan dan pengendalian dengan bahan kimia, Pengelolaan Perlindungan Diri dan Pengelolaan dan Pengendalian secara terpadu secara keseluruhan sudah berjalan cukup baik

Hal itu terlihat bahwa dari 185 orang petugas pemantau jentik yang menjadi responden 32 orang atau $17,3 \%$ petugas menjalankan upaya kegiatan pengendalian DBD dengan Baik, 97 orang responden atau $52,4 \%$ kegiatan pengendalian DBD sudah berjalan cukup Baik dan sebanyak 56 orang petugas yang menjadi responden atau $30,3 \%$ responden menyampaikan bahwa upaya kegiatan pengendalian DBD di Kabupaten Tangerang masih berjalan kurang baik.

\section{Hasil Analisis Bivariat}

Analisis bivariat dilakukan untuk menguji besaran Hubungan atau pengaruh antara Faktor-faktor keaktifan petugas dengan upaya kegiatan pengendalian 
penyakit Demam Berdarah di Kabupaten Tangerang. Hasil analisis secara Simultan Hubungan Variabel Faktor-faktor Keaktifan petugas yang terdiri dari Pengetahuan Petugas, Etos dan Minat Kerja, Pembagian Jelajah Kerja, Uraian Pedoman Kerja, Pelatihan dan Pengembangan Karir, Pengakuan dan Exsistensi Diri, Kompensasi Imbalan Atau Reward, Ketersediaan Fasilitas Kerja, Motivasi Pribadi, Dukungan Keluarga, Sistem Kepemimpinan, Lingkungan Kerja Terhadap Upaya Pengendalian Penyakit Demam Berdarah Dengue di Kabupaten Tangerang menunjukan hubungan atau pengaruh yang sangat kuat hal itu dibuktikan dengan nilai $F$ hit sebesar 43,864 dan nilai sign. sebesar 0,000 .

Besar Hubungan yang diperoleh dari hasil pengujian Corellasi antara Variabel Faktor-faktor Keaktifan petugas yang terdiri dari Pengetahuan Petugas, Etos dan Minat Kerja, Pembagian Jelajah Kerja, Uraian Pedoman Kerja, Pelatihan dan Pengembangan Karir, Pengakuan dan Exsistensi Diri, Kompensasi Imbalan Atau Reward, Ketersediaan Fasilitas Kerja, Motivasi Pribadi, Dukungan Keluarga, Sistem Kepemimpinan, Lingkungan Kerja Terhadap Upaya Pengendalian Penyakit Demam Berdarah Dengue di Kabupaten Tangerang menunjukan nilai hubungan yang sangat kuat yaitu sebesar $0,868^{\mathrm{a}}$

Nilai R determinan antara Faktor-faktor Keaktifan petugas yang terdiri dari pengetahuan petugas, etos dan minat kerja, pembagian jelajah kerja, uraian pedoman kerja, pelatihan dan pengembangan karir, pengakuan dan exsistensi diri, kompensasi imbalan atau reward, ketersediaan fasilitas kerja, motivasi pribadi, dukungan keluarga, sistem kepemimpinan, lingkungan kerja terhadap upaya pengendalian Penyakit Demam Berdarah Dengue di Kabupaten Tangerang adalah sebesar 0.754 atau 75,4\% Faktor-faktor keaktifan petugas dapat menjelaskan upaya pengendalian Penyakit Demam Berdarah Dengue di Kabupaten Tangerang dan sisanya dapat dijelaskan oleh faktor-faktor lain.

\section{Hasil Analisis Multivariat}

Analisis multivariat ini dilakukan untuk menganalisis nilai hubungan pengaruh langsung dan tidak langsung dan total pengaruh yang terjadi, langkah analisis multivariat ini dilakukan dengan langkah langkah sebagai berikut :

a. Melakukan pengujian validitas, reliabilitas dan normalitas variabel dan indikatornya

b. Seleksi indikator dan permodelan

c. Menghitung besaran pengaruh langsung tidak langsung dan total pengaruh.

Untuk lebih jelasnya hasil analisis multivariat ini disajiikan sebagai berikut ini :

\section{1). Pengujian Validitas Reliabilitas dan Normalitas Seleksi Faktor.}

Uji persyaratan analisis ini ditujukan untuk menguji kelayakan variabel dalam hal ini validitas, reliabilitas dan normalitas data dari setiap variabel yang diajukan agar dapat dilakukan uji lanjutan yaitu untuk kepentingan pengujian bivariat dan multivariat, adapun hasil uji persyaratan analisis yang telah dilakukan dipaparkan seperti pada tabel berikut ini: 
Tabel 7

Pengujian Validitas Reliabilitas dan Normalitas Variabel X, Y1, Y2, dan Z

\begin{tabular}{|c|c|c|c|c|c|c|c|}
\hline \multirow{2}{*}{ Variabel Penelitian } & \multicolumn{2}{|c|}{$\begin{array}{l}\text { Uji Validitas } \\
\text { variabel }\end{array}$} & \multicolumn{2}{|c|}{$\begin{array}{c}\text { Uji Relia } \\
\text { bilitasvariabel }\end{array}$} & \multicolumn{2}{|c|}{$\begin{array}{l}\text { Uji Normalitas } \\
\text { variabel }\end{array}$} & \multirow{2}{*}{ Keterangan } \\
\hline & $\begin{array}{l}\text { Nilai } \\
\text { R hit }\end{array}$ & $\begin{array}{l}\text { Nilai } \\
\text { R tab }\end{array}$ & $\begin{array}{c}\text { Nilai } \\
\text { C.Alpha }\end{array}$ & $\begin{array}{c}\text { Nilai } \\
\text { Reliabity }\end{array}$ & $\begin{array}{c}\text { Nilai } \\
\text { Skewness }\end{array}$ & $\begin{array}{c}\text { Std. } \\
\text { Normalitas }\end{array}$ & \\
\hline $\begin{array}{l}\text { Variabel Faktor X1 } \\
\text { S.D X12 Faktor } \\
\text { Keaktifan Petugas }\end{array}$ & $\begin{array}{l}0.687 \\
* *\end{array}$ & 0,144 & 0,842 & 0.868 & $-2,324$ & $<3.0$ & $\begin{array}{l}\text { Data valid } \\
\text { reliabel, } \\
\text { normal }\end{array}$ \\
\hline $\begin{array}{l}\text { Variabel Y2 Upaya } \\
\text { Pengendalian DBD }\end{array}$ & $\begin{array}{c}0.813 \\
* * \\
\end{array}$ & 0,144 & 0,808 & 0.868 & 1,078 & $<3.0$ & $\begin{array}{l}\text { Data valid } \\
\text { reliabel dan } \\
\text { normal }\end{array}$ \\
\hline
\end{tabular}

\section{Sumber : Data Primer Terolah}

Berdasarkan pada Table 7 menunjukan bahwa variabel faktor-faktor keaktifan petugas sudah valid, begitu juga dengan variabel upaya pengendalian DBD menunjukkan nilai korellasi yang kuat dan signifikan, mendekati nilai 1 , oleh sebab itulah secara keseluruhan variabel-variabel penelitian ini sudah valid dan dapat dilanjutkan untuk pengujian reliabilitasnya. Dengan variabel yang valid akan menghasilkan analisis yang ajeg dan konsisten. Secara keseluruhan nilai alpha croncbach dari variabel penelitian ini adalah sebesar 0,868. Nilai ini menunjukkan bahwa secara simultan variabel penelitian ini menghasilkan nilai alpha sebesar 0,868. Besral (2012) , Muchtaruddin Mansyur ( 2016) menyatakan bahwa apabila nilai Alpa Croncbach mendekati angka 1 dapat dikatakan bahwa tingkat reliabilitas variabel tersebut sangatlah kuat mendekati sempurna.

Variabel Faktor-Faktor Keaktifan Petugas didapat nilai kemiringannya sebesar - 2,324, Variabel Y2 Upaya Pengendalian DBD nilai kemiringannya sebesar 1,078 dari hasil perhitungan diatas maka dapat dikatakan semua variabel yang ada memiliki data yang berdistribusi normal variabel yang dianalisis besaran nilai Skewnessnya atau kemiringannya kurang dari 3, Besral (2012) mengemukakan bahwa apabila nilai standard error nya dibagi dengan nilai skewnessnya hasilnya kurang dari 3 maka data yang ada sudah berdistribusi normal. Oleh sebab itulah variabel keaktifan petugas dan Upaya pengendalian DBD datanya sudah valid,reliabel dan normal.

\section{2). Seleksi Faktor dan Permodelan Akhir.}

Berdasarkan hasil pemilihan kandidat multivariat yang telah dilakukan melalui hasil perhitungan statistic dan beberapa kali pengujian maka diperoleh variabel yang memenuhi syarat yang dipaparkan pada Tabel 8 seperti beri berikut ini :

\section{Tabel 8}

Hasil Seleksi Bivariat Hubungan faktor-faktor keaktifan petugas pemantau jentik terhadap upaya kegiatan pengendalian penyakit Demam Berdarah di Kabupaten Tangerang.Tangerang

\begin{tabular}{lccc}
\hline Variabel Penelitian & $\begin{array}{c}\text { Nilai } \\
\text { Cronbach's Alpha }\end{array}$ & $\begin{array}{c}\text { Nilai } \\
\text { Cronbach's Alpha } \\
\text { Secara Keseluruhan }\end{array}$ & Keputusan \\
\hline $\begin{array}{l}\text { Dukungan Keluarga } \\
\text { Ketersediaan }\end{array}$ & 0.891 & 0.901 & $\begin{array}{c}\text { Valid dan Reliabel } \\
\text { Masuk Model }\end{array}$ \\
Fasilitas Kerja & 0.889 & 0.901 & $\begin{array}{c}\text { Valid dan Reliabel } \\
\text { Masuk Model }\end{array}$
\end{tabular}




\begin{tabular}{lccc}
$\begin{array}{l}\text { Sistem } \\
\text { Kepemimpinan }\end{array}$ & 0.872 & 0.901 & $\begin{array}{c}\text { Valid dan Reliabel } \\
\text { Masuk Model } \\
\text { Valid dan Reliabel } \\
\text { Lingkungan Kerja }\end{array}$ \\
$\begin{array}{lccc}\text { Masuk Model } \\
\text { Motivasi Pribadi }\end{array}$ & 0.874 & 0.901 & $\begin{array}{c}\text { Valid dan Reliabel } \\
\text { Masuk Model } \\
\text { Valid dan Reliabel } \\
\text { Masuk Model }\end{array}$ \\
\hline
\end{tabular}

Berdasarkan Tabel 8 diatas diperoleh 6 (enam) faktor yang sangat valid dan reliabel dimana nilai Cronbach alpha tiap variabel yang diuji nilainya sudah diatas 0,800 dan secara keseluruhan nilai Cronbach's Alpha nya diperoleh 0,901 mendekati 1 / sempurna. Variabel yang memiliki nilai Cronbach alpha sempurna diurutkan dari paling besar ke paling kecil adalah sebagai berikut :

1. Motivasi Pribadi dengan nilai Cronbach sebesar 0,894

2. Dukungan keluarga dengan nilai Cronbach sebesar 0,891

3. Ketersediaan fasilitas dengan nilai Cronbanch sebesar 0,889

4. Pengetahuan Petugas dengan nilai Cronbach sebesar 0,878

5. Lingkungan Kerja dengan nilai Cronbach sebesar 0,874

6. Sistem Kepemimpinan dengan nilai Cronbach sebesar 0,872

Faktor-faktor keaktifan petugas pemantau jentik yang drop terdiri dari kegiatan pelatihan dan kejelasan pengembangan karier, pengakuan eksistensi diri, etos dan minat kerja, pembagian wilayah kerja, uraian pedoman kerja, kompensasi imbalan dan reward yang diterima dikeluarkan dari analisis lanjutan.

Pemilihan variabel faktor ini bertujuan untuk memastikan faktor-faktor tersebut sudah benar-benar memenuhi syarat pengujian lebih lanjut untuk memaksimalkan pembuatan permodelan multivariat yang akan disampaikan.

Untuk keperluan Permodelan multivariat ini faktor-faktor yang sudah terpilih diatas kemudian dilakukan kembali pengujian dengan melakukan analisis regressi. Pengujian dilakukan dengan menganalisis nilai $\mathrm{t}$ - Value dengan tingkat signifikansi sebesar 0.05. Nilai t-value dalam program amos.23 adalah nilai dari Critical Ratio (CR) pada Regression weights : (Grouf Number 1 - Default model). Ketentuan yang dipakai adalah apabila nilai $\mathrm{CR} \geq 1,967$ atau nilai Probabilitas $(\mathrm{P}) \leq 0.05$ maka $\mathrm{Ho}$ ditolak dan Ha diterima. Hasil pengolahan oleh Amoss 23 tampak pada Tabel 9 berikut ini:

Tabel 9

Regression Weights: (Group number 1 - Default model)

Faktor keaktifan petugas, upaya kegiatan pengendalian DBD di Kabupaten Tangerang

\begin{tabular}{|c|c|c|c|c|c|c|c|c|}
\hline \multicolumn{3}{|c|}{$\begin{array}{l}\text { Keterkaitan antar Variabel } \\
\text { Penelitian }\end{array}$} & \multirow{2}{*}{$\begin{array}{c}\text { Estimate } \\
0.244\end{array}$} & \multirow{2}{*}{$\begin{array}{c}\begin{array}{c}\text { Std } \\
\text { Estimate }\end{array} \\
\mathbf{0 . 2 3 3}\end{array}$} & \multirow{2}{*}{$\begin{array}{l}\text { S.E. } \\
.072\end{array}$} & \multirow{2}{*}{$\begin{array}{l}\text { C.R. } \\
3.382\end{array}$} & \multirow{2}{*}{$\frac{\mathbf{P}}{* * *}$} & \multirow{2}{*}{$\begin{array}{c}\text { Label } \\
\text { par_9 }\end{array}$} \\
\hline $\begin{array}{l}\text { Variabel Y2.31 } \\
\text { Upaya } \\
\text { Pengendalian }\end{array}$ & $<---$ & $\begin{array}{l}\text { Pengetahuan } \\
\text { petugas }\end{array}$ & & & & & & \\
\hline $\begin{array}{l}\text { Variabel Y2.31 } \\
\text { Upaya } \\
\text { Pengendalian }\end{array}$ & $<---$ & $\begin{array}{l}\text { Motivasi } \\
\text { Pribadi }\end{array}$ & 0.126 & 0.113 & .057 & 2.188 & 0.029 & par_18 \\
\hline $\begin{array}{l}\text { Variabel Y2.31 } \\
\text { Upaya } \\
\text { Pengendalian }\end{array}$ & $<---$ & $\begin{array}{l}\text { Lingkungan } \\
\text { kerja }\end{array}$ & 0.002 & 0.002 & .075 & 0.032 & 0.975 & par_19 \\
\hline
\end{tabular}




\begin{tabular}{|c|c|c|c|c|c|c|c|c|}
\hline \multicolumn{3}{|c|}{$\begin{array}{l}\text { Keterkaitan antar Variabel } \\
\text { Penelitian }\end{array}$} & \multirow{2}{*}{$\begin{array}{c}\text { Estimate } \\
0.357\end{array}$} & \multirow{2}{*}{$\begin{array}{c}\begin{array}{c}\text { Std } \\
\text { Estimate }\end{array} \\
\mathbf{0 . 3 7 1}\end{array}$} & \multirow{2}{*}{$\begin{array}{l}\text { S.E. } \\
.067\end{array}$} & \multirow{2}{*}{$\begin{array}{l}\text { C.R. } \\
5.331\end{array}$} & \multirow{2}{*}{$\begin{array}{c}\mathbf{P} \\
* * *\end{array}$} & \multirow{2}{*}{$\begin{array}{l}\text { Label } \\
\text { par_27 }\end{array}$} \\
\hline $\begin{array}{l}\text { Variabel Y2.31 } \\
\text { Upaya } \\
\text { Pengendalian }\end{array}$ & $<---$ & $\begin{array}{l}\text { Sistem } \\
\text { kepemimpinan }\end{array}$ & & & & & & \\
\hline $\begin{array}{l}\text { Variabel Y2.31 } \\
\text { Upaya } \\
\text { Pengendalian }\end{array}$ & $<---$ & $\begin{array}{l}\text { Ketersediaan } \\
\text { fasilitykerja }\end{array}$ & 0.061 & 0.055 & .064 & 0.946 & 0.344 & par_28 \\
\hline $\begin{array}{l}\text { Variabel Y2.31 } \\
\text { Upaya } \\
\text { Pengendalian }\end{array}$ & $<---$ & $\begin{array}{l}\text { Dukungan } \\
\text { keluarga }\end{array}$ & 0.147 & 0.154 & .055 & 2.656 & 0.008 & par_29 \\
\hline
\end{tabular}

Sumber : Data Primer Terolah

Dari tabel 9 diperoleh data bahwa faktor-faktor yang berpengaruh secara positip terhadap upaya kegiatan pengendalian DBD di Kabupaten Tangerang setelah dilakukan lagi seleksi yaitu :

1. Pengetahuan petugas besar pengaruh 0,233, 23,3\%

2. Motivasi Pribadi, besar pengaruh sebesar 0,113, 11,3\%

3. Sistem Kepemimpinan besar pengaruh sebesar $0,371,37,1 \%$

4. Dukungan Keluarga, besar pengaruh sebesar $0,154,15,4 \%$

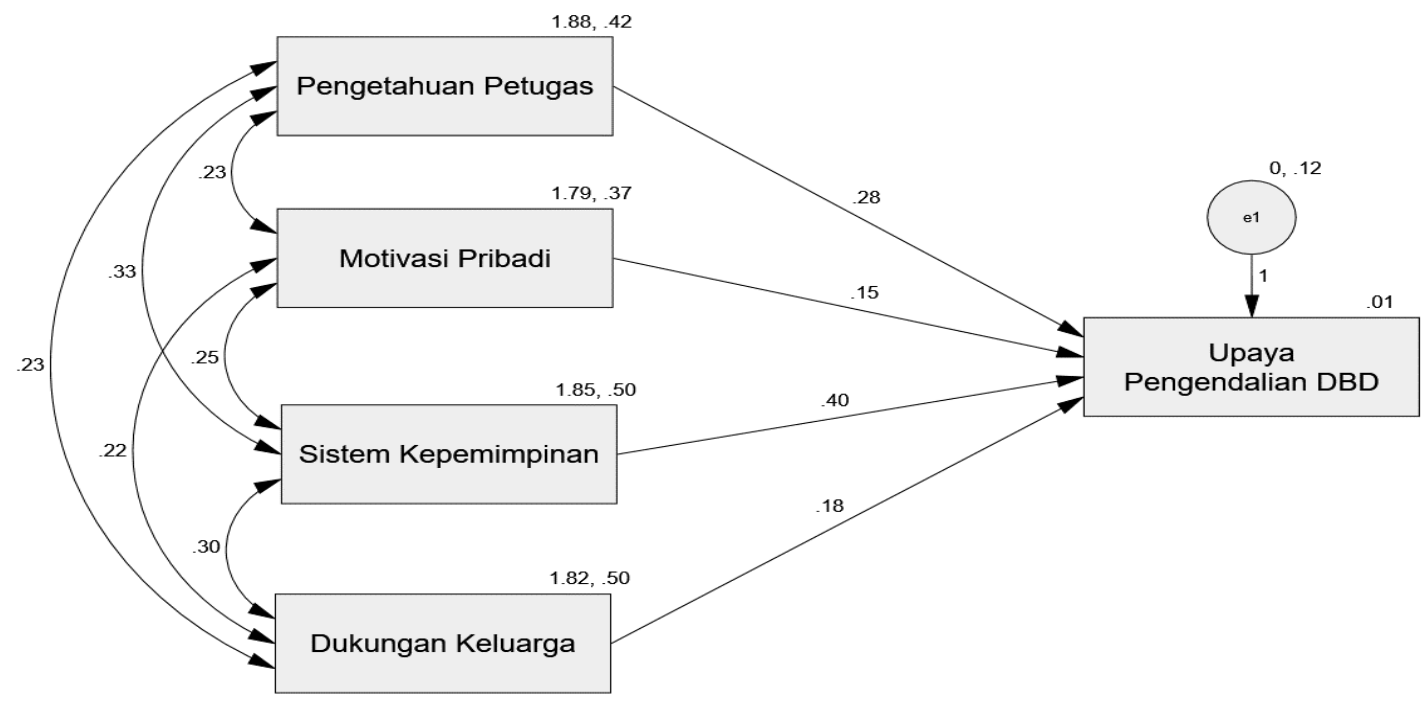

Gambar 1 : Analisis pengaruh langsung dan pengaruh tidak langsung antar variabel

Dalam kaitan Gambar 1 terlihat bahwa faktor-faktor yang ada saling berkaitan dan berpengaruh satu sama lainnya, dan faktor keaktifan petugas yang terseleksi untuk uji multivariat didapat ada 4 (Empat) Faktor yang secara keseluruhan berpengaruh yaitu sistem kepemimpinan, pengetahuan
Berdasarkan data pada Tabel 9 di atas maka dapat ditentukan permodelan multivariat seperti di bawah ini. Permodelan akhir ini dimaksudkan untuk mengetahun besaran pengaruh langsung dan tidak langsung secara keseluruhan. Berdasarkan permodelan variabel diatas diperolehlah permodelan akhir yang digambarkan seperti berikut ini: 
Tabel 10

Pengaruh Langsung

Standardized Direct Effects (Group number 1 - Default model)

Faktor keaktifan petugas, terhadap upaya kegiatan pengendalian DBD

di Kabupaten Tangerang

\begin{tabular}{lcccc}
\hline \multirow{2}{*}{ Variabel dan Indikator } & \multicolumn{4}{c}{ Faktor-faktor Keaktifan Petugas } \\
\cline { 2 - 5 } & MP & DK & PP & SK \\
\hline $\begin{array}{l}\text { Variabel } \\
\begin{array}{l}\text { Upaya Kegiatan Pengendallian DBD } \\
\text { di Kabupaten Tangerang }\end{array}\end{array}$ & $\mathbf{0 , 1 3 3}$ & $\mathbf{0 , 1 8 8}$ & $\mathbf{0 , 2 6 9}$ & $\mathbf{0 , 4 1 4}$ \\
\hline
\end{tabular}

Sumber : Data Primer Terolah

Berdasarkan Tabel 10 terlihat bahwa dari sekian banyak faktor yang dianalisa ternyata hanya 4 (empat) Faktor yang terpilih yang berpengaruh terhadap upaya pengendalian DBD di Kabupaten Tangerang, yaitu Motivasi pribadi sebesar 0,133 atau $13,3 \%$, Dukungan Keluarga 0,188 atau $18,8 \%$, pengetahuan petugas 0,269 atau $26,9 \%$ dan Sistem
Kepemimpinan sebesar 0,414 atau $41,4 \%$. Dari hasil pengolahan analisa tidak ditemukan faktor yang berpengaruh tidak langsung semuanya berpengaruh langsung terhadap upaya pengendalian DBD di Kabupaten Tangerang, sehingga diperoleh pengaruh total yang dapat dianalisa kembali pada tabel 11 berikut ini.

Tabel 11

Pengaruh Total

Standardized Total Effects (Group number 1 - Default model)

Faktor keaktifan petugas terhadap upaya kegiatan pengendalian DBD di Kabupaten Tangerang

\begin{tabular}{lcccc}
\hline \multirow{2}{*}{ Variabel dan Indikator } & \multicolumn{4}{c}{ Faktor-faktor Keaktifan Petugas } \\
\cline { 2 - 5 } & MP & DK & PP & SK \\
\hline $\begin{array}{l}\text { Variabel Upaya Kegiatan Pengendallian } \\
\text { DBD di Kabupaten Tangerang }\end{array}$ & $\mathbf{0 , 1 3 3}$ & $\mathbf{0 , 1 8 8}$ & $\mathbf{0 , 2 6 9}$ & $\mathbf{0 , 4 1 4}$ \\
\hline
\end{tabular}

Sumber : Data Primer Terolah

Pada tabel 11 diperoleh data bahwa faktor yang memiliki total pengaruh paling besar terhadap upaya pengendalian DBD adalah secara berurutan adalah sistem kepemimpinan sebesar 41,4\%, pengetahuan petugas $26,9 \%$, dukungan keluarga $18,8 \%$ dan motipasi pribadi sebesar $13,3 \%$.

\section{3). Faktor Dominan.}

Hasil seleksi bivariat ditemukan bahwa ada enam faktor yang memengaruhi, faktor tersebut terdiri dari :
a. Motivasi Pribadi
b. Dukungan keluarga
c. Ketersediaan fasilitas

d. Pengetahuan Petugas

e. Lingkungan Kerja

f. Sistem Kepemimpinan

Dari enam faktor tersebut kemudian diolah kembali untuk kepentingan pengujian multivariat dan ada dua faktor yang drop yaitu
a. Ketersediaan Fasilitas
b. Lingkungan Kerja

Kemudian ditemukan 4 faktor yang terseleksi sebagai berikut :

a. Motivasi Pribadi

b. Dukungan keluarga

c. Pengetahuan Petugas

d. Sistem Kepemimpinan 
Berdasarkan hasil analisis pengamatan dan pengolahan baik pendekatan univariat,bivariat dan multivariat seperti diatas ternyata pada akhirnya ditemukan faktor yang dominan memengaruhi upaya kegiatan pengendalian DBD di Kabupaten Tangerang, faktor-faktor itu adalah sebagai berikut sistem kepemimpinan sebesar $41,4 \%$, pengetahuan petugas $26,9 \%$, dukungan keluarga $18,8 \%$ dan motipasi pribadi sebesar 13,3\%. Dari keempat Faktor yang ditemukan tersebut diketahui bahwa Sistem kepemimpinan adalah faktor yang sangat dominan dalam upaya pengendalian DBD di Kabupaten Tangerang disusul dengan tingkat pengetahuan petugas akan penyakit Demam Berdarah.

Keberhasilan Pengendalian Penyakit DBD di Kabupaten Tangerang yang secara umum kegiatannya terdiri dari

1. Pengelolaan dan pengendalian kondisi Lingkungan

2. Pengelolaan dan pengendalian DBD secara Biologis

3. Pengelolaan dan pengendalian dengan bahan kimia

4. Pengelolaan dan Perlindungan Diri

5. Pengelolaan dan Pengendalian terpadu

Tingkat keberhasilannya sangat ditentukan oleh sistem kepemimpinan dan pengetahuan petugasnya, artinya apabila sistem kepemimpinan yang dijalankan dalam kegiatan pengendalian DBD kemudian didukung dengan pengetahuan petugas yang baik maka sudah barang tentu penyakit DBD yang ada akan terkendali dengan baik.

\section{KESIMPULAN}

Berdasarkan hasil pengolahan dalam penelitian ini maka dapat disimpulkan beberapa hal antara lain sebagai berikut :

1. Faktor-faktor keaktifan petugas yang terdiri dari kegiatan Pelatihan dan kejelasan pengembangan karier, Pengakuan eksistensi diri, Etos dan minat kerja, Pembagian wilayah kerja, Uraian pedoman kerja, Dukungan keluarga, Kompensasi imbalan dan reward yang diterima, Ketersediaan Fasilitas Kerja, Sistem Kepemimpinan, Lingkungan Kerja, Motivasi Pribadi, dan Pengetahuan Petugas secara mayoritas sudah berjalan cukup baik.

2. Upaya Kegiatan Pengendalian Penyakit Demam Berdarah Dengue di kabupaten Tangerang yang terdiri dari Kegiatan Pengelolaan dan pengendalian kondisi Lingkungan, Kegiatan Pengelolaan dan pengendalian DBD secara Biologis, Pengelolaan dan pengendalian dengan bahan kimia, Pengelolaan Perlindungan Diri dan Pengelolaan dan Pengendalian secara terpadu secara keseluruhan sudah berjalan cukup baik.

3. Hasil analisis secara parsial memperlihatkan Hubungan Variabel Faktor-faktor Keaktifan petugas yang terdiri dari Pengetahuan Petugas, Etos dan Minat Kerja, Pembagian Jelajah Kerja, Uraian Pedoman Kerja, Pelatihan dan Pengembangan Karir, Pengakuan dan Exsistensi Diri, Kompensasi Imbalan Atau Reward, Ketersediaan Fasilitas Kerja, Motivasi Pribadi, Dukungan Keluarga, Sistem Kepemimpinan, Lingkungan Kerja Terhadap Upaya Pengendalian Penyakit Demam Berdarah Dengue di Kabupaten Tangerang menunjukan hubungan atau pengaruh yang sangat kuat hal itu dibuktikan dengan nilai $\mathrm{F}$ hit sebesar 43,864 dan nilai sign. sebesar 0,000 .

4. Hasil Analisis Multivariat ditemukan faktor yang dominan memengaruhi upaya kegiatan pengendalian DBD di Kabupaten Tangerang, faktor-faktor 
itu adalah sebagai berikut sistem kepemimpinan sebesar 41,4\%, pengetahuan petugas $26,9 \%$, dukungan keluarga $18,8 \%$ dan motipasi pribadi sebesar $13,3 \%$.

5. Dari keempat Faktor yang ditemukan tersebut diketahui bahwa Sistem kepemimpinan adalah faktor yang sangat dominan dalam upaya pengendalian DBD di Kabupaten Tangerang disusul dengan tingkat pengetahuan petugas akan penyakit Demam Berdarah.

\section{SARAN}

Berdasarkan hasil dan kesimpulan yang diperoleh dari hasil penelitian dan pengamatan, maka peneliti menyarankan sebagai berikut :

1. Faktor-faktor keaktifan petugas yang dianalisis memiliki hubungan pengaruh yang sangat kuat terhadap upaya pengendalian DBD, pelaksanaannya juga sudah terbilang cukup baik maka sudah selayaknya Dinas terkait lebih mengoptimalkan kembali faktor-faktor tersebut.

2. Faktor dominan yang ditemukan terdiri dari sistem kepemimpinan, pengetahuan petugas, dukungan keluarga, dan motivasi pribadi maka baik dinas terkait, maupun petugas sudah selayaknya meningkatkan sinergi yang baik antar keduanya, baik dalam pengelolaan program yang dijalankan atau kegiatan-kegiatan yang tengah dilakukan dalam upaya pengendalian DBD di Kabupaten Tangerang.

3. Dalam penelitian ini ditemukan bahwa keberhasilan upaya pengendalian DBD sangat ditentukan oleh sistem kepemimpinan dan pengetahuan petugasnya, artinya apabila sistem kepemimpinan yang dijalankan dalam kegiatan pengendalian DBD kemudian didukung dengan pengetahuan petugas yang baik maka sudah barang tentu penyakit DBD yang ada akan terkendali dengan baik, maka dari itu DInas terkait, petugas pemantau jentik lebih meningkatkan leadership dan peningkatan pengetahuan petugasanya. Kepemimpinan yang baik akan memotivasi dan mendorong masyarakat untuk bekerja dan bergerak, Pengetahuan petugas yang baik akan memberikan penyadaran bagi masyarakat tentang pentingnya pengendalian DBD di wilayahnya, begitu juga dengan motivasi pribadi dan tentunya adanya dukungan keluarga yang positip akan meningkatkan kinerja petugas dalam upaya pengendalian DBD di Kabupaten Tangerang.

\section{DAFTAR PUSTAKA}

Wage Nurmaulina dan Dyah Wulan Sumekar,2016, Upaya Pengendalian Vektor Demam Berdarah Dengue, Aedes aegypti L. Menggunakan Bioinsektisida. Majority | Volume 5 | Nomor 2 | April 2016.

\section{KLB DBD, Tangerang Kerahkan 880}

Jumantik diakses pada https://metro.tempo.co/read/news/201 6/02/06/083742760/klb-dbdtangerang-kerahkan-880-jumantik Sabtu, 06 Februari 2016 | 10:00 WIB diakses pada hari selasa, 23 mei 2016

Nonce N.Legi,Dkk,2015, Faktor Yang Berhubungan Dengan Keaktifan Kader Posyandu Di Wilayah Kerja Puskesmas Ranotana Weru. GIZIDO Volume 7 No. 2 November 2015.

\section{Sugiyono, 2015,Statistik Nonparametris untuk Penelitian,Alfabeta Bandung,2015} ,2005. Statistika Untuk Penelitian. Bandung: CV. Alpabeta 
Ni Putu Desi Ary Sandhi,Dkk,2014 Pengaruh Faktor Motivasi Terhadap Kinerja Juru Pemantau Jentik Dalam Pelaksanaan Pemberantasan Sarang Nyamuk Di Kecamatan Denpasar Selatan Tahun 2013, Halaman 120 132 Community Health VOLUME II $\square$ No 1 Januari 2014

Sandhi, NP \& Martini, NK. 2014.

Pengaruh faktor motivasi terhadap kinerja juru pementau jentik dalam pelaksanaan pemberantasan sarang nyamuk di Kecamatan Denpasar Selatan tahun 2013. Artikel Penelitian Comunity Health. Vol. 2 No. 1.

Arietha Novera Hutapea,dkk, 2013,Gambaran Kinerja Kader Jumantik Dalam Pemberantasan Sarang Nyamuk Dbd Di Kecamatan Padang Hulu Kota Tebing Tinggi Tahun 2013, FKM USU.2013.

Malaptha Ginting,2013, Analisis Determinan Kinerja Petugas Surveilans Demam Berdarah Dengue Di Kota Pematang Siantar Tahun 2013, Tesis,Program Studi S2 Ilmu Kesehatan Masyarakat Fakultas Kesehatan Masyarakat Universitas Sumatera Utara Medan 2013.

Dinas Kesehatan Kabupaten Tangerang, 2013. Bidang Pengendalian Masalah Kesehatan, Kasus DBD di Kabupaten Tangerang.

Erdi Komara,2012,Kinerja Jumantik dan Program Pengendalian Demam Berdarah Dengue (DBD) di Kecamatan Tebet Tahun 2011,Skripsi , FKM UI, 2012.

Yuniati., 2012. Pengaruh Sanitasi Lingkungan Pemukiman terhadap Kejadian Demam Berdarah Dengue (DBD) di Daerah Aliran Sungai Deli Kota Medan,Tesis S2, Medan: Universitas Sumatera Utara.
Achmadi, U.F., 2012. Manajemen Penyakit Berbasis Wilayah, Edisi Revisi, Jakarta:Raja Grafindo Persada.

Kementrian Kesehatan Republik Indonesia,2012, Petunjuk Teknis Pemberantasan Sarang Nyamuk Demam Berdarah Dengue (PSN DBD) oleh Juru Pemantau Jentik (Jumantik), Direktorat Jenderal Pengendalian Penyakit Dan Penyehatan Lingkungan, Direktorat Pengendalian Penyakit Bersumber Binatang 2012.

Kementrian Kesehatan Republik Indonesia,2011, Modul Pengendalian Demam Berdarah Dengue, Direktorat Jenderal Pengendalian Penyakit Dan Penyehatan Lingkungan 2011

Sandjojo,Nidjo,DR,M.Sc.,2011 Metode Analisis Jalur (Path Anaysis) dan Aplikasinya,Pustaka Sinar Harapan Jakarta.

Moleong,J,Lexy,2011,Metodologi

Penelitian Kualitatif,Remaja Rosda Karya,Bandung.

Aryu Candra,2010, Demam Berdarah Dengue: Epidemiologi, Patogenesis, dan Faktor Risiko Penularan. Aspirator Vol. 2 No. 2 Tahun 2010 : $110-119$.

Wuryanto, 2010, Hubungan lingkungan kerja dan karakteristik individu dengan kepuasan kerja perawat di Rumah Sakait Umum Daerah Tugurejo Semarang. Tesis. Fakultas Ilmu Keperawatan. Universitas Indonesia

Pambudi, 2009, Faktor-Faktor Yang Mempengaruhi Partisipasi Kader Jumantik Dalam Pemberantasan Dbd Di Desa Ketitang Kecamatan Nogosari Kabupaten Boyolali Tahun 2009, Program Studi Kesehatan Masyarakat 
Fakultas Ilmu Kesehatan Universitas Muhammadiyah Surakarta 2009.

Rumanti,S.,2008.Determinan Tindakan Masyarakat Dalam Pemberantasan Malaria di Kecamatan Tanjung Balai Kabupaten Asahan,Tesis,Medan : Universitas Sumatera Utara.

Indri Yuswandari,2008,Faktor-faktor yang mempengaruhi keaktifan Jumantik,Tesis,FKM UNAIR 2008.

Ida Siti Zubaedah,2007,Hubungan FaktorFaktor Sumber Daya Manusia Terhadap Kinerja Petugas Pokja DBD Tingkat Kelurahan Di Kota Tasikmalaya, Tesis,Universitas Diponegoro Semarang.

Amrul, H., 2007. Hubungan Pemberantasan Sarang Nyamuk (PSN) dan Pencegahan gigitan Nyamuk Aedes aegypti dengan Kejadian Demam Berdarah Dengue di Kota Bandar Lampung, Tesis, Jakarta: Universitas Indonesia.

Kusnendi,DR,MS,2007 .Model - model Persamaan Struktural Satu dan Multigroup sampel dengan LISREL.Bandung:CV.Alfabeta

Anton, S., 2008. Hubungan Perilaku Tentang PSN dan Kebiasaan Keluarga Dengan Kejadian DBD di Kecamatan Medan Perjuangan Kota Medan, Tesis,Semarang:Universitas Dipenogoro.

Departemen Kesehatan R.I., 1998. Penemuan dan Tatalaksana Penderita Demam Berdarah Dengue, Buku Paket B,Jakarta: Direktorat Jenderal PPM \& PPL.

$\begin{array}{lr}\text { Kesehatan 2003. Kajian } & \text { Masalah } \\ \text { Dengue,Badan } & \begin{array}{r}\text { Berdarah } \\ \text { Penelitian }\end{array}\end{array}$

Pengembangan kesehatan, Jakarta: Ditjen PP\&PL. 